\title{
Endomycorrhizal Fungi and Opuntia ficus-indica Seed Germination on a Lunar Regolith Simulant
}

\author{
Gertrud Konings-Dudin*, Michelle J. Butcher, Jesus A. Castor-Macías, Benjamin Kohanloo, \\ Michelle Garcia \\ Biology Department, El Paso Community College, EI Paso, USA \\ Email: "gkonings@epcc.edu
}

Received 20 June 2014; revised 10 July 2014; accepted 5 August 2014

Copyright (C) 2014 by authors and Scientific Research Publishing Inc.

This work is licensed under the Creative Commons Attribution International License (CC BY).

http://creativecommons.org/licenses/by/4.0/

c) (i) Open Access

\begin{abstract}
Endomycorrhizal fungi play an important role in the survival of plants on poor soils. Planting seeds into lunar soil at a lunar colony will be a challenge for seeds of any plant. The seeds will need a special microbial "tool kit" that will help them germinate and the young seedlings establish themselves. In this study, seeds of the prickly pear cactus, Opuntia ficus-indica, were chosen to examine the presence of fungus spores in the soil, inside the seeds and after germination in the rhizosphere, roots and other tissues of the young seedlings. The nutrient poor lunar regolith simulant JSC-1A was used as autoclaved or untreated growth medium. The mycorrhizal fungus Trichoderma viride was predominantly identified on the roots of new seedlings. This fungus also demonstrated the strongest effect on the germination rate of the seeds in comparison with other fungi isolated from the rhizosphere of Opuntia plants. T. viride was not detected within seeds and also not within seedlings, besides the root tips, whereas an arbuscular mycorrhizal Glomus species was seed-borne and present throughout most of the seedling. A close association between $T$. viride and a Glomus species associated with $O$. ficus-indica is demonstrated through light microscopic and electron microscopic images of the outside and inside root tips of the seedlings.
\end{abstract}

\section{Keywords}

Endomycorrhizal Fungi, Seed Germination, Lunar Regolith Stimulant, Nutrient Poor Soil, Opuntia ficus-indica

\section{Introduction}

The prickly pear cactus, Opuntia ficus-indica, is an important crop plant from Mexico that is well suited for hot,

${ }^{*}$ Corresponding author.

How to cite this paper: Konings-Dudin, G., Butcher, M.J., Castor-Macías, J.A., Kohanloo, B. and Garcia, M. (2014) Endomycorrhizal Fungi and Opuntia ficus-indica Seed Germination on a Lunar Regolith Simulant. Advances in Microbiology, 4, 616-626. http://dx.doi.org/10.4236/aim.2014.410068 
semiarid and arid environments and was therefore chosen by our team as a possible starter plant for an extraterrestrial colony. It establishes itself easily and is one of the most productive crop plants known [1]. The lunar regolith simulant JSC-1A is a volcanic, nutrient-poor and dusty soil that simulates the soil retrieved from the moon by NASA and is used to study the suitability of plants for agriculture in a lunar colony. It is also well suited for a study of associated microbes of plants that grow very successfully on nutrient-poor soils and the role that these microbes may play in their success. The symbiotic relationship of fungi with roots in the rhizosphere at the soil-root interface is a well-known phenomenon and assumed to be present in almost all plants, including the cacti of the genus Opuntia [2]. The mycorrhizae are formed by fungal hyphae growing either on the outside of plant roots (ectomycorrhizae) or into the roots (endomycorrhizae). Thus the mycorrhizal fungi increase the root surface and extend the plant's reach for nutrients. They are known to play a major role in phosphate uptake of the plant and in accessing other nutrients in poor soils as well [3]-[6]. AM fungi reportedly also increase the production of dry matter in seedlings of the cactus Pachycereus pectin-aboriginum [7]. According to Pope (1993) [8], the growth of endomycorrhizal fungi is promoted by high light intensity and poor soil conditions. Especially on desert soils they may therefore help plants acquire the minerals they need from the soil. The degree of root colonization, however, also varied and showed seasonal site variation on the prickly pear Opuntia humifusa in the study of Whitcomb (2000) [2]. Therefore the author suggests classifying a "plant's mycorrhizal status based on the ecological condition in which they are found". Dubrovsky and North (2002) [9] recognize three species of the genus Glomus as inhabitants of the rhizosphere of the Opuntia species they studied. These form arbuscular-mycorrhizal (AM) fungus associations between the zygomycete fungus with coenocytic hyphae and the plant. They are diagnosed by the presence of arbuscules in the cortical root cells and of terminal vesicles that contain oil droplets [8]. The hyphae extend from the infected root into the adjacent soil or may connect root to root. The spores of AM fungi remain in the soil in sporocarps, but may also become windborne. According to Barrow et al. (2008) [10], endosymbiotic fungi even grow into developing seed embryos and are thus vertically transmitted by seeds, as reported from C3 forage grasses.

The seeds of the prickly pear cacti of the genus Opuntia are known for their strong physiological dormancy and a low growth potential of their embryos, which means that their seeds do not germinate easily, an adaptation to desert environments [11]. The seeds have a very hard endocarp so that the dormant seed embryo cannot break. Delgado-Sanchez et al. (2010; 2011) [12] [13] found an effect of Penicillium chrysogenum, a Phoma species, and Trichoderma koningii on breaking germination resistance in Opuntia seeds. Since these fungi were observed growing on the testa of all germinated seeds and eroding the funiculus, the authors interpreted the resistance to germinate as a mechanical problem. This idea goes along with the commonly used methods of breaking Opuntia seed dormancy through scarification methods, which involve treatment with sulfuric acid, cold treatment and/or rubbing with sandpaper [14].

In this study the effect of different soil fungi, including mycorrhizal fungi, on the germination rate of seeds of the prickly pear cactus, Opuntia ficus-indica, was evaluated, and the presence of endomycorrhizal fungi on and in the seeds and the seedlings growing on lunar regolith simulant JSC-1A was studied with the use of light and scanning electron microscopy (SEM). The importance of these fungi for the seed germination on a nutrient poor soil and the establishment of the seedlings are discussed.

\section{Methods}

Seeds of Opuntia ficus-indica were collected from mature fruits (tunas) obtained in supermarkets and stored in paper bags at room temperature to allow for a normal aging process to overcome their dormancy. At the time of usage, they were between 2 - 3 years old.

\subsection{Determination of Fungi on and Inside Seeds}

The presence of fungi on and inside the seeds was studied using untreated and surface-sterilized seeds. Alcohol, often together with hypochloride, is commonly used to sterilize the outer surface of seeds, including seeds of Opuntia species [12] [15]. To surface-sterilize the seeds for planting, they were washed in 70\% ethanol for 10 min, rinsed four times in sterile, distilled water and dried before planting. Surface-sterilization of the seeds for fungus growth on agar included a bleach treatment. They were submerged in 70\% ethanol for 30 sec, then for 10 min in a solution of $1 \%$ hypochlorite prepared of household bleach, followed by four rinses in distilled water. The seeds were then placed whole or crushed on sterile Sabouraud Dextrose Agar (Becton Dickinson) in Petri 
dishes (SDA plates). The plates were incubated in the dark at room temperature. Samples of the growing colonies were placed on microscopic slides and stained with Lactophenol cotton blue (LPCB) to check for presence of bacteria and fungi, and to identify the fungi microscopically. Bacteria were also Gram stained.

\subsection{Mycorrhizal Fungi and Seed Germination}

To study the fungus or fungi growing on the roots of seedlings, we designed several planting experiments. The lunar regolith simulant JSC-1A (Orbitec, LLC) was used as a planting soil for the seeds. Preliminary studies in our lab demonstrated that prickly pear cacti grow well on the regolith. First the native germination rate of our $O$. ficus-indica seeds on JSC-1A was determined. 20 seeds were placed into plain JSC-1A held within a coffee filter in a plastic planting pot and kept moist with distilled water (Table 1, \#0). The roots of the freshly sprouted seedlings were swabbed with sterile cotton swabs to prepare streaks on SDA plates. The resulting fungal cultures were later used to study their effect on the germination rate of the O. ficus-indica seeds from the same batch.

In these germination experiments JSC-1A was used either untreated or autoclaved for 30 min at $121^{\circ} \mathrm{C}$. The presence of fungus spores in the untreated and autoclaved soil was determined through sprinkling a small sample onto sterile SDA plates. The SDA plates were kept in the dark at room temperature to promote fungus growth.

For the first series of germination experiments (Table 1) autoclaved soil was used to study the effect of a mycorrhizal fungus on the seed germination rate of $O$. ficus-indica seeds. The planting pots, coffee filters and plastic bags needed were first placed overnight under UV light in the laboratory hood for sterilization purposes. The planting procedure was performed under application of aseptic techniques. First the coffee filters were placed into the planting pots. Then autoclaved JSC-1A was added into the coffee filter and sterile distilled water added to moisten the soil well. The seeds were then placed onto the moist soil and pushed slightly into it, but care was taken to not cover them. The control pots were transferred at once into plastic Ziploc bags and the bags closed by $3 / 4$ allowing for air exchange, but preventing airborne spores from falling onto the soil. To the other pots samples of the fungal culture, obtained from the root streak of seedlings described above (seedlings from experiment \#0, Table 1), representing a green mycrorrhizal fungus (identified as Trichoderma viride), were streaked with a sterile loop onto the soil close to the seeds. For experiment \#3 (Table 1) surface-sterilized seeds were used. These planting pots were then too placed into plastic bags and closed as described above. All germination experiments were kept at room temperature on a plant stand with artificial lighting. The humidity in the plastic bags was kept high by pouring sterile distilled water into the bags on demand. Twice a week the planting pots were checked for growth. The bags were opened under the laboratory hood when a seedling was visible and the root was swabbed to prepare a fungal culture.

In a second experiment the seed germination effect of the green mycorrhizal fungus (T. viride) (from experiment \#0, Table 1) was compared to that of other soil fungi. Only untreated seeds were used in this experiment, and different soil fungi were added to untreated JSC-1A soil, in which also fungi originally present in the soil were allowed to interact with the introduced fungus. The fungi used for infection were isolated from swabs of JSC-1A soil, in which adult Opuntia plants were grown under carbon dioxide stress. We decided to use these

Table 1. Seed germination results with and without $T$. viride addition.

\begin{tabular}{|c|c|c|c|c|c|c|}
\hline \multicolumn{7}{|c|}{ Seed Germination } \\
\hline Exp \# & Timespan of Exp & $\begin{array}{c}\text { JSC-1A } \\
\text { Untreated } \\
\text { \# of seeds/ resulting } \\
\text { seedlings }\end{array}$ & $\begin{array}{c}\text { Autoclaved JSC-1A } \\
\text { plain (control) } \\
\text { \# of seeds/ } \\
\text { \# of seedlings }\end{array}$ & $\begin{array}{c}\text { TOTAL } \\
\text { \% germination }\end{array}$ & $\begin{array}{c}\text { Autoclaved JSC-1A } \\
\text { plain } \\
\text { Fungus added } \\
\text { \# of seeds/\# of } \\
\text { seedlings }\end{array}$ & $\begin{array}{c}\text { TOTAL } \\
\text { \% germination }\end{array}$ \\
\hline 0 & $8 \mathrm{wk}$ & $20 / 11$ & & 55 & & \\
\hline 1 & $12 \mathrm{wk}$ & & $27 / 0$ & 0 & $27 / 8$ & 29.6 \\
\hline 2 & $14 \mathrm{wk}$ & & $50 / 0$ & 0 & $50 / 21$ & 42 \\
\hline 3 & $6 \mathrm{mo}$ & & $\begin{array}{c}10 / 0 \\
\text { surface sterilized }\end{array}$ & 0 & $\begin{array}{c}10 / 1 \\
\text { surface sterilized }\end{array}$ & 10 \\
\hline
\end{tabular}


fungi, since they were present around the roots of these extremely stressed plants that survived the stress treatment well. Five different fungus colonies and one bacterial culture were isolated from their soil previously in our lab. All experiments of this second seed germination series, including a control in which the soil was not infected, were prepared in parallel. The resulting germination rates (Table 2) were scored as positive (germination) or negative (no germination). SDA cultures were prepared from swabs of the roots of each seedling shortly after germination and of some seedlings again at a later time to determine the type of fungus growing on the root.

\subsection{Fungus Staining and SEM Studies}

From at least one seedling of each experiment with a positive result, roots were used for mycorrhizal staining followed by light microscopic studies. For the mycorrhizal fungus staining of the seedling roots the method described by Vierheilig et al. (1998) [16] was applied. The roots were rinsed well in tap water, boiled in $10 \% \mathrm{KOH}$ for $5 \mathrm{~min}$, stained for $3 \mathrm{~min}$ in a boiling hot 5\% ink/vinegar solution (blue Pelican ink) and rinsed for 20 min with tap water containing a few drops of household vinegar. Other roots were used untreated for observation in the Scanning Electron Microscope (Hitachi TM-1000).

\subsection{Mycorrhizal Fungi within Seedlings}

Three seedlings from different pots were surface-sterilized, in order to look for evidence of fungi within the seedling itself. We followed the surface-sterilizing procedure described by Shekhawat et al. (2013) [17] for leaves and roots. Each plant was immersed into $75 \%$ ethanol for $1 \mathrm{~min}$, then into an aqueous solution of sodium hypochloride (household bleach) for $15 \mathrm{~min}$, followed by washing in $70 \%$ ethanol for $5 \mathrm{sec}$ and rinsed in sterile distilled water. The seedling and its roots were then cut into segments, sliced open and placed on different SDA plates to examine fungus growth.

\subsection{Interaction of an Endophytic with a Mycrorhizal Fungus}

Finally, we also wanted to observe the interaction of the most prevalent green fungus obtained from root swabs of the seedlings in all our studies with one of the fungus species (Aspergillus terreus) identified from the crushed surface-sterilized seeds. In duplicate cultures $(n=2)$, both were placed on the same SDA plates near the edge and on opposite sides of each other and studied for their growth behavior over a period of three weeks.

\section{Results}

On SDA plates with untreated JSC-1A many bacterial colonies grew first and a few green fungal colonies appeared after one week in culture. Autoclaved JSC-1A soil samples on SDA still produced a few bacterial, but no fungal colonies. Soil samples taken immediately after seed germination produced bacterial and fungal colonies on SDA. Microscopic analysis of samples from the colonies on the latter culture revealed a Penicillium sp., a Glomus sp., and cluster-forming, rod-shaped bacteria (Figure 1).

Table 2. Seed germination after addition of different soil fungi and bacteria.

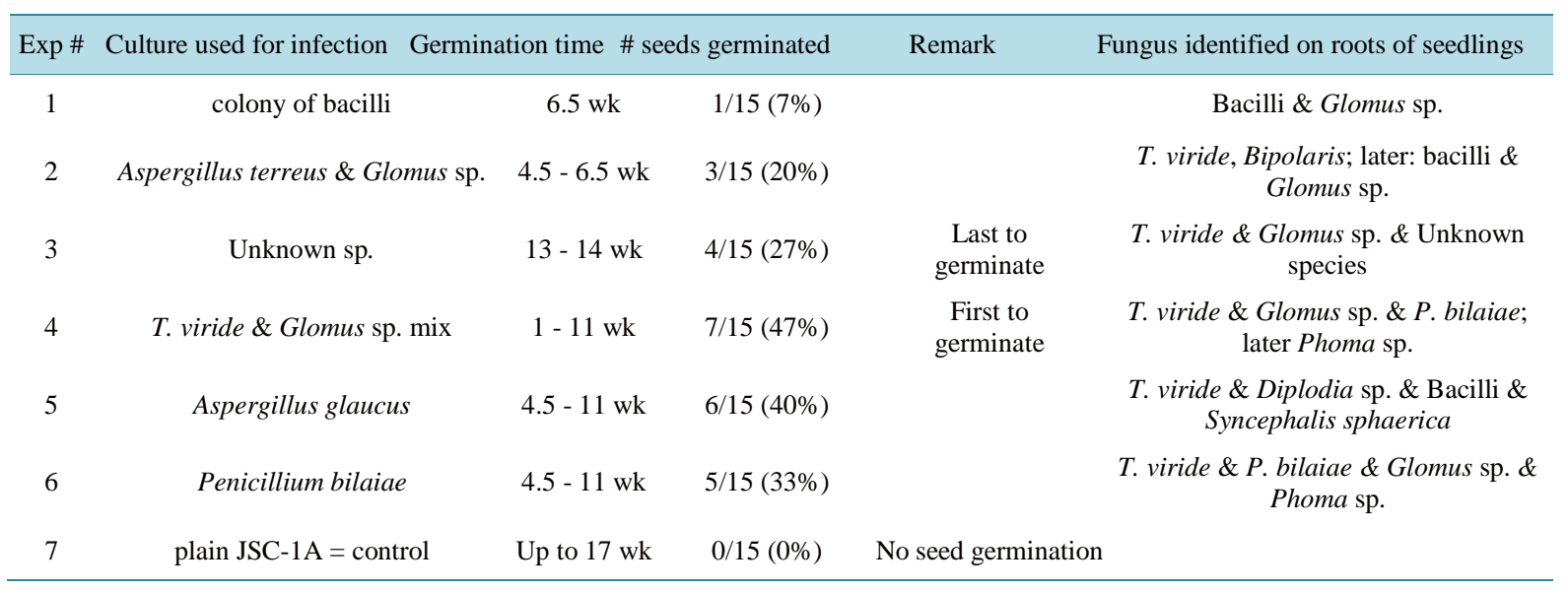




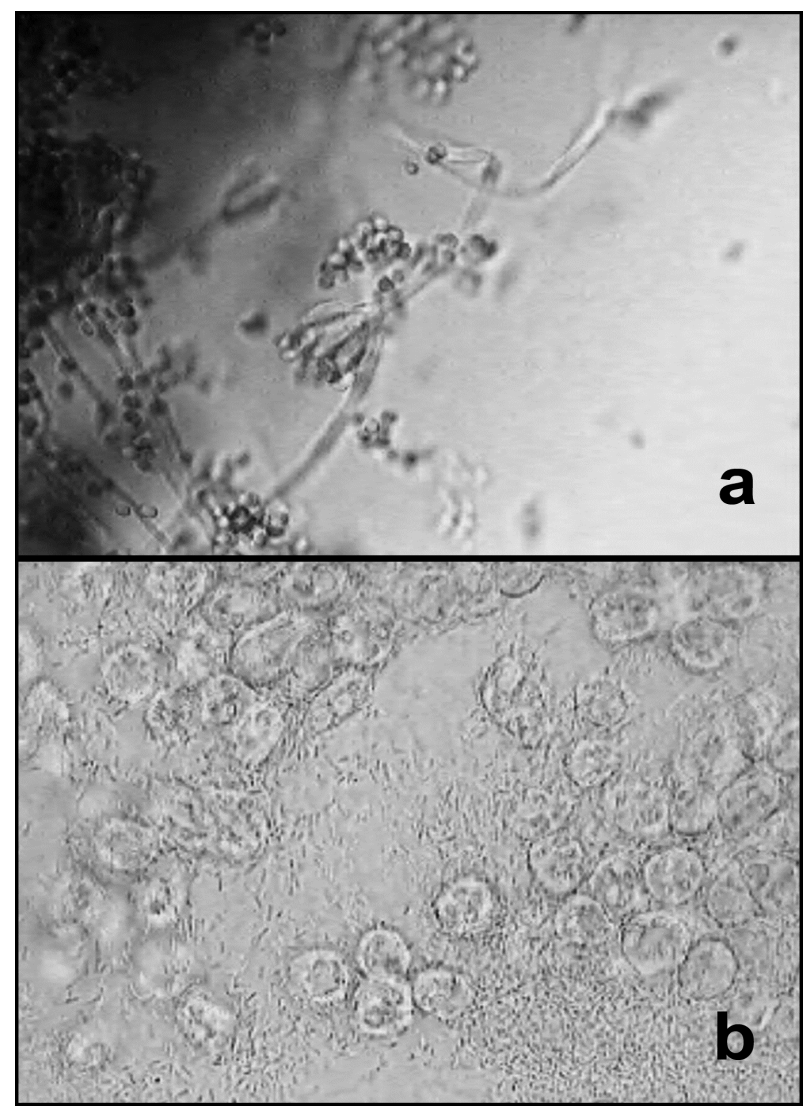

Figure 1. Example Light microscopic images of fungus cultures from (previously autoclaved) JSC-1A soil sampled after seed germination-(a) Penicillium sp.; (b) Glomus sp. and bacilli (Magnification: $1000 \times$ ).

Untreated whole seeds placed on SDA produced no fungus growth at all, but some bacterial colonies, which were identified as small rods. From surface-sterilized crushed seeds a diversity of bacterial and fungal cultures grew on SDA. Among the fungi were: Aspergillus terreus, a Phoma sp., a Glomus sp., and a Penicillium sp., as demonstrated through light microscopic examination after LPCB staining (Figure 2). Bacteria were not identified. Not every seed produced the same fungi and bacteria. None of the tested surface sterilized seeds germinated during the experiment.

The regular (control) germination rate of non-surface-sterilized seeds on untreated JSC-1A was 55\% (Table 1, exp. 0). Root swab cultures from the seedlings revealed predominantly a first white and later green colored fungus, which was identified as Trichoderma viride (Figure 3). The addition of the T. viride fungus from SDA cultures of the root swabs from control seedlings (exp. 0) had an obvious effect on the germination rate of the $O$. ficus-indica seeds in the autoclaved JSC-1A soil as recorded in Table 1. Autoclaving the soil had reduced the total number of seed germination from $55 \%$ to $0 \%$ in the cultures without fungus addition. Adding $T$. viride to the seeds restored the germination rate to $29.6 \%$ and $42 \%$ respectively. In the exp. 1 and 2 (Table 1 ) the seeds were untreated, for exp. 3 (Table 1) seeds surface-sterilized with alcohol were used. Surface-sterilizing the seeds did affect germination negatively, with only one seed germinating very late in the culture where $T$. viride was added. Even an incubation period of six months did not improve this result.

Mainly $T$. viride was identified as the mycorrhizal fungus on the roots of all freshly germinated seedlings. Also present, but less frequent were Aspergillus nidulans, Penicillium sp., a Glomus sp., and a Phoma sp. Together with the $T$. viride fungus gram ${ }^{+}$bacilli and spore aggregates were regularly present (Figure 3 ).

In the second series of seed germination experiments the effect of different soil fungi and a bacterial colony on the seed germination rate of $O$. ficus-indica seeds was compared with the effect of the $T$. viride fungus. All seeds used in this series were untreated, planted into untreated JSC-1A and observed over a period of 3.5 months. 


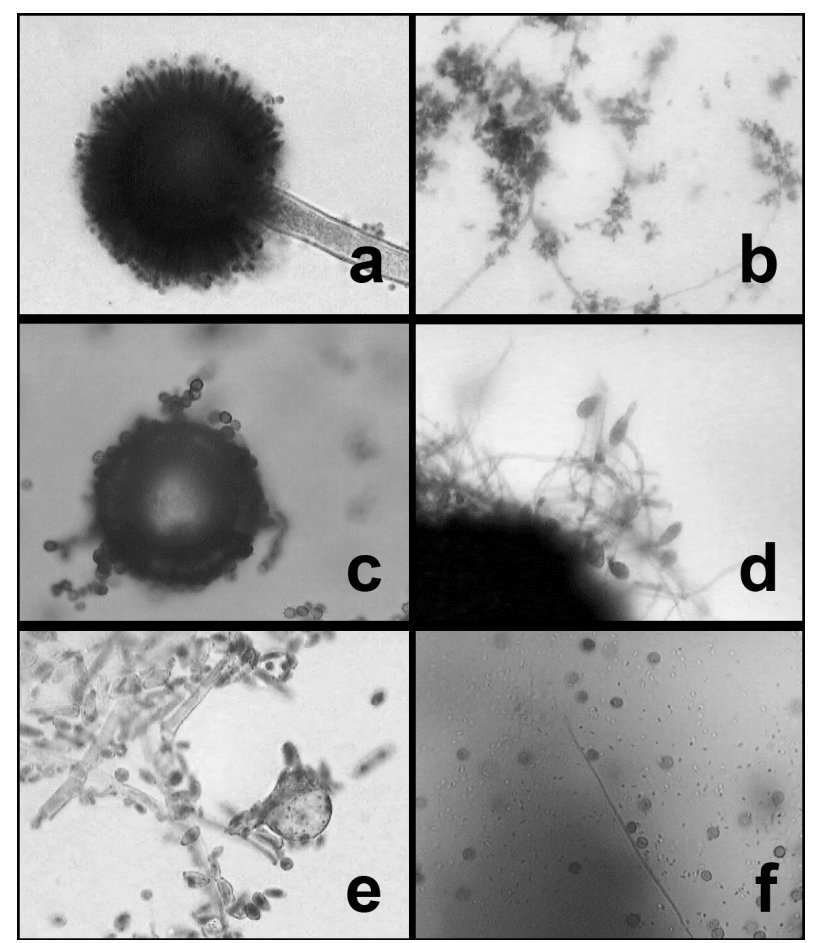

Figure 2. Identified from surface sterilized crushed seed cultures were (a) Aspergillus terreus; (b) Penicillium sp.; (c) (d) Phoma sp., and (e) (f) Glomus sp. Magnification: 1000× (a)-(e), $400 \times(f)$.

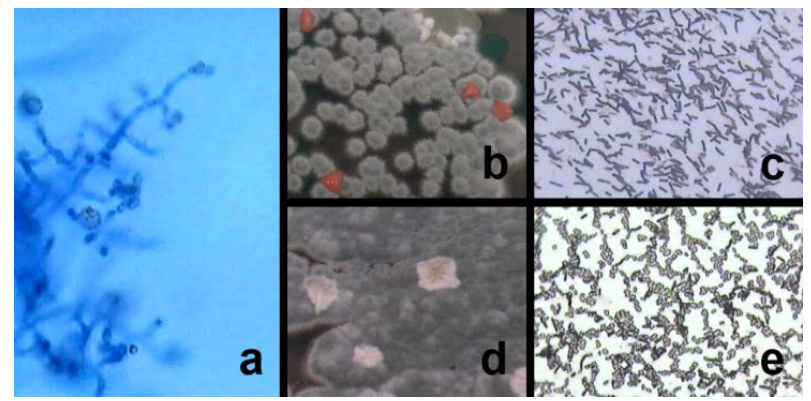

Figure 3. The green endomycorrhizal fungus Trichoderma viride (a) with pink colonies of gram + bacilli (b) on SDA; (c) After Gram-staining and with white colonies of gram + bacilli and spore aggregates (d) on SDA; (e) After Gram-staining. (Magnification $1000 \times(a, c, e)$ ).

The germination time, germination rate and the fungi applied at the start of the experiment are listed in Table 2. In addition the fungi present in the rhizosphere of the freshly sprouted seedlings are also listed in this table. The highest germination rate was obtained by infecting the soil with a mixture of $T$. viride and Glomus sp., which yielded a $47 \%$ germination rate. The second best germination rate (40\%) was produced by adding Aspergillus glaucus to the seeds, followed by Penicillium bilaiae with the third highest germination rate (33\%). Except for experiment \#1, in which only one seed germinated, all swab cultures from seedling roots revealed the presence of $T$. viride and a Glomus sp., irrespective of the fungal culture originally used for infection. Some of the root swab cultures immediately showed strong presence of the $T$. viride fungus while it took some time to see it growing in others. We found that the earlier the green $T$. viride fungus appeared in the root swab cultures, the earlier the seeds had germinated in that experiment. Weak presence of $T$. viride thus resulted in poor seed germination. 
Roots of seedlings from these infection experiments were studied in the SEM and the results compared to those obtained with light microscopy after mycorrhiza staining. Both examinations revealed that the roots were covered by mycorrhizal fungi-including the seedling of experiment \#1 and that the Glomus sp. and T. viride fungi grew intertwined at the surface and into the inside of the roots (Figure 4). The hyphae of Glomus are coenocytic and wide, whereas those of $T$. viride are septate, thinner and branched at right angles. Glomus, a common AM fungus, forms vesicles inside the root, as depicted in the light-microscopic pictures (Figure 4). The vesicles inside the roots are clearly visible. Outside the root the characteristic sporangium of $T$. viride is recognizable (Figure 4(d) and Figure 4(e)).

A thin septate hypha extends from the sporangium into the root. Glomus sporangia are visible in the SEM picture from the root of a seedling (Figure 5(a)). In our SEM examination we found on several occasions penetration of Glomus hyphae into root cells (Figure 5(b)).

From sliced sections of the root tip of surface sterilized seedling roots we grew both T. viride and a Glomus sp. on SDA plates. Higher up within surface-sterilized roots and within the actual seedlings, we did not detect any $T$. viride, but a Glomus sp., Aspergillus sp. and a Phoma sp. were found to grow even high up inside the seedling.

The interaction of the endomycorrhizal fungi $T$. viride and Glomus with a pathogenic fungus, Aspergillus terreus, one of the fungi present inside the $O$. ficus-indica seeds, was demonstrated on SDA plates. Within two days the endomycorrhizal fungi produced a secretion that stained the agar yellow. Within a week the Aspergillus appeared contained in growth by the faster growing $T$. viride and Glomus sp. mix and a dense rim of $T$. viridesurrounded A. terreus.

\section{Discussion}

On the nutrient poor soil JSC-1A good mycorrhizal fungus growth on and around the roots of $O$. ficus-indica seedlings could be documented through light and electron microscopic studies, confirming the results of Pope

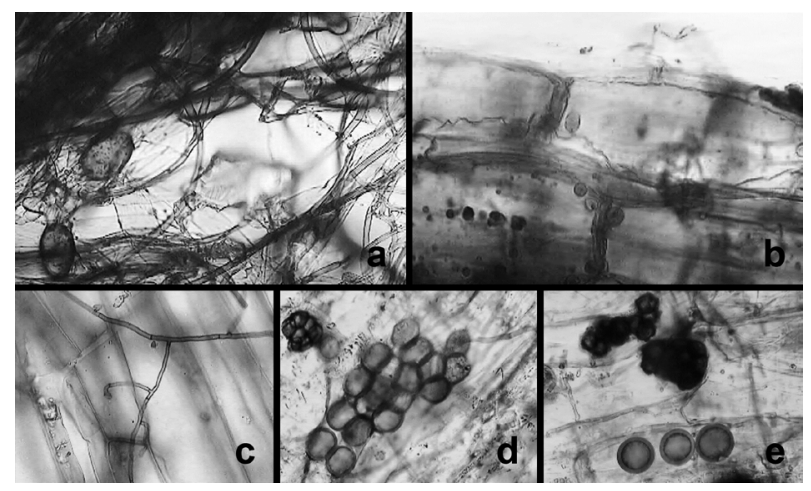

Figure 4. Mycorrhizae on roots of seedlings: septate hyphae of $T$. viride grow alongside the coenocytic Glomus hyphae outside of the root (a); Septate hyphae show penetration into the root (c). Vesicles formed by the AM fungus are visible (b) (d) (e); and on the root sporangia at the end of septate hyphae resemble those of $T$. viride (d) \& (e) (Magnification 1000×).
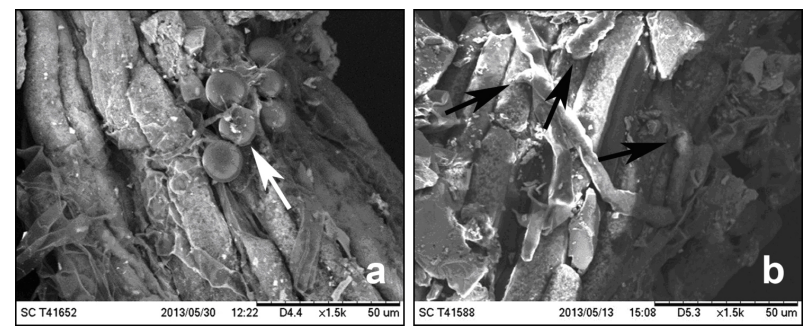

Figure 5. (a) Spores of the AM fungus on the root of a seedling (white arrow); (b) Penetration of the hyphae into the root cells are indicated by black arrows (SEM magnification 1500×). 
(1993) [8] that poor soil conditions promote the presence of mycorrhizal fungi in the rhizosphere of plants. The endomycorrhizal fungus, $T$. viride, increased in our studies the germination rate of $O$. ficus-indica seeds by $29.6 \%$ and $42 \%$ respectively on the sterilized soil and under the conditions provided in this study (Table 1). On the roots of the young seedlings the presence of $T$. viride was regularly confirmed, even when other fungi or only bacteria were added to the soil together with the seeds (Table 2). The stronger the presence of $T$. viride was on the seedlings' roots, the earlier the seeds had germinated. Though Aspergillus and Penicillium fungi also affected the germination rate of the seeds positively, the presence of $T$. viride in root swab cultures of the seedlings indicates that their role in the rhizosphere of the young seedling might be supportive of $T$. viride. Kumar (2012) [18] found the highest mycorrhizal root colonization in his studies with Menthaspicata when Glomus mossae and T. viride were inoculated together. The additional presence of an AM fungus, in our experiments an unidentified Glomus species, is demonstrated by the occurrence of vesicles and arbuscules in root tips of seedlings through light microscopic observation after mycorrhizal staining (Figure 4). AM fungi are Glomeromycota [4]. Their hyphae are coenocytic and the spores form terminal on them [19], which we could demonstrate in SEM studies (Figure 5(a)). Endomycorrhizal fungi penetrate the root of the plant and enter the cells where they will live as intracellular symbionts. Penetration sites of the fungus into the root were recognized in our studies in the SEM (Figure 5(b)). De Jaeger et al. (2010) [20] describe that Trichoderma harzianum is penetrating its host plant through the arbuscular mycorrhizal fungus Glomus. In our studies with mycorrhizal fungus staining the septate and coenocytic hyphae seem to grow next to each other outside and inside the root (Figure 4). We could therefore not confirm a similar interaction of the two fungi in $O$. ficus-indica roots in our test system.

Glomus forms "Chlamydospores singly or in tight clusters (sporocarp), sometimes covered with hyphal peridium”, as described by Schenck and Smith (1982) [21]. Observations in the SEM (Figure 5(a)) revealed similar structures in our studies. Our combined data thus confirm also the presence of a Glomus sp. as the AM fungus in the rhizosphere of the $O$. ficus-indica seedlings on JSC-1A.

Mycorrhizal fungi reportedly protect the plant from pathogens by producing signaling compounds like abscisic acid [22]. Ellouze et al. (2012) [23] studied the effect of phytochemicals produced by the plant roots on fungus spore germination and concluded that the plants modify the microbial community of the soil to their advantage and the interaction is under genetic control. In our studies the T. viride_Glomus mixture produced a yellow secretion that prevented other fungi from growing on the same plate. Both endomycorrhizal fungi seem to be needed to secure the germination and establishment of the young $O$. ficus-indica seedling on the nutrient poor JSC-1A soil.

In this study we also demonstrate the presence of fungal spores and bacteria within the seeds of $O$. ficus-indica (Figure 2). Hijri et al. (2002) [19] found spores of pathogenic fungi inside the spores of an arbuscular mycorrhizal fungus without causing symptoms, which they interpreted as a possible weapon of the fungus against non-mycorrhizal competitors. The cultivation of a Glomus sp. among other fungi from sterilized seeds in our study (Figure 2) confirms the finding of Barrow et al. (2008) [10] that AM fungi can be transmitted through seeds. We speculate that the presence of fungal spores and bacteria in the seeds might give cacti an advantage on poor soils, which might also be poor of spores of mycorrhizal fungi that the plant could acquire. Thus the seeds of O. ficus-indica might be equipped with a "survival kit" to inhabit inhospitable areas. Dastager et al. (2010) [24] found that among phosphate solubilizing fungi, Aspergillus and Penicillium species were the most prominent. In our experiments both these two genera were represented in the rhizosphere of Opuntia seedlings (Table 2) and even within seeds themselves (Figure 2), another indication that their seeds are especially equipped for survival on nutrient poor soils.

AM fungi also interact with bacteria living on the roots and within the rhizosphere, but also incorporate bacteria as endosymbionts. The interaction between fungi and bacteria in the rhizosphere is another important finding of studies on plant fungus interactions. Dastager et al. (2010) [24] report on a plant growth promoting Micrococcus species. In our study the addition of a prevalent bacterial colony to $O$. ficus-indica seeds did not enhance the germination rate of the seeds. However, the presence of bacteria around and within the root tip and within the seeds seems to suggest a possible role in seed germination and/or establishment of the seedling. Puente et al. (2004) [5] found hardly any fungus spores in soil of arid areas they studied in Mexico. However, a large bacterial population was present in the rhizosphere of the plants, including cacti, which may indicate a stronger role of bacteria than fungi on dry soils.

T. viride was not growing in our cultures of surface-sterilized normal or crushed seeds, though its presence was striking in the swabs of the roots from seedlings and even within the root tips that were surface-sterilized. It 
therefore could be acquired from the soil, though we could not prove its presence in autoclaved soil. An interaction of $T$. viride with other fungi and bacteria - probably with the help of a Glomus sp.-in the early stages of the establishment of the seedling - probably led to the persistence of $T$. viride at the end, no matter what the initial culture condition was. This fungus is known for its protective function in different plants and is now exploited in agriculture as a natural biocontrol agent. T. viride and other Trichoderma species were successfully tested against pathogens of the onion [25]. In Turkey Trichoderma species have been introduced as a biocontrol agent against soil-borne diseases of several crops [26]. Its inhibitory effect on pathogenic fungi was recently also reported by Bouziane et al. (2011) [27], who found it effective against most pathogens they tested, including three Phoma species. In their paper Phoma is considered a pathogen of Zea mays. In our study the presence of a Phoma species in the seeds and seedlings that were healthy looking, seems to indicate that this fungus is seed-borne and might also play a special role in the endomycorrhizal interplay during the germination process of $O$. ficus-indica seeds and the establishment of the young seedlings in our test system. A synergistic interaction of AM fungi with T. viride and a subsequent increase in root colonization is reported by Kumar (2012) [18]. Sjoeberg (2005) [28] reports in her thesis on AM fungi about their protective effect against the plant pathogenic fungus Bipolaris sorokiniana. A Biplolaris species could also be documented in the rhizosphere of some seedlings in our experiments and also within seeds. Similar to Phoma, the Bipolaris fungus might play a role in establishing the seedling. In agreement with Hijri et al. (2002) [19], these fungi might serve as a possible weapon against non-mycorrhizal competitors. T. viridae is presently on the market as an antagonistic fungus to protect crops from soil borne diseases. Still, Dalling et al. (2011) [29] criticize in their review that the role of seed-borne fungi in the defense against soil-borne pathogens has been underestimated and overlooked too often.

The finding that alcohol sterilized seeds were negatively affected in their germination capability was a surprising result of our study, especially since alcohol is commonly used in seed sterilization procedures and was found to even enhance germination in some [15]. In their study these authors found that high concentrations of alcohol can be lethal to turfgrass seeds, which they studied. Alcohol seems to affect $O$. ficus-indica seedlings similarly; however more studies are needed to confirm this finding.

\section{Conclusion}

In conclusion, the endomycorrhizal fungus $T$. viride demonstrates a close interaction with a Glomus species during and after germination of $O$. ficus-indica seeds on the nutrient poor lunar regolith simulant JSC-1A soil. They both grow in the root tip, however only the Glomus sp. was present within the rest of the seedling. The Glomus sp. is also passed on through the seed, together with bacteria and some pathogenic fungi, whose role still has to be evaluated.

\section{Acknowledgements}

Michelle J. Butcher, Jesus A. Castor-Macías, Ben Kohanloo, and Michelle Garcia and research reported in this publication were supported in part by the Research Initiative for Scientific Enhancement (RISE) Program funded by the National Institute of General Medical Sciences of the National Institutes of Health under Award Number R25GM060424. G. Konings-Dudin research was supported by the El Paso Community College (EPCC). The content is solely the responsibility of the authors and does not necessarily represent the official views of the National Institutes of Health or EPCC.

We thank Dan Hawk, University of Wisconsin Green Bay, for providing the JSC-1A lunar regolith simulant.

\section{References}

[1] Acevedo, E., Badilla, I. and Nobel, P.S. (1983) Water Relations, Diurnal Acidity Changes, and Productivity of a Cultivated Cactus, Opuntia ficusindica. Plant Physiology, 72, 775-780. http://dx.doi.org/10.1104/pp.72.3.775

[2] Whitcomb, S.A. (2000) Mycorrhizal Associations in Opuntia humifusa in Southern Illinois. Ph.D. Thesis, Southern Illinois University Carbondale, Carbondale, 85.

[3] Monreal, M. and Grant, C. (2002) Effects of Soil Microbiota on Fertility under Direct Seeding. Proceedings of the 14th Annual Conference of the Saskatchewan Soil Conservation Association, Proceedings from the 14th Annual Meeting, Conference and Trade Show of the Saskatchewan Soil Conservtion Association, 13-14 February 2002, Regina, SK. http://www.ssca.ca/index.php/59-past-conferences/131-2002-direct-seeding-conference

[4] Bonfante, P. (2003) Plants, Mycorrhizal Fungi and Endobacteria: A Dialog among Cells and Genomes. Biological 
Bulletin, 204, 215-220. http://dx.doi.org/10.2307/1543562

[5] Puente, M.E., Bashan, Y., Li, C.Y. and Lebsky, V.K. (2004) Microbial Populations and Activities in the Rhizoplane of Rock-Weathering Desert Plants. I. Root Colonization and Weathering of Igneous Rocks. Plant Biology, 6, 629-642. http://dx.doi.org/10.1055/s-2004-821100

[6] Olsson, P.A., Rahm, J. and Aliasgharzad, N. (2010) Carbon Dynamics in Mycorrhizal Symbioses Linked to Carbon Costs and Phosphorus Benefits. FEMS Microbiology Ecology, 72, 123-131. http://dx.doi.org/10.1111/j.1574-6941.2009.00833.X

[7] Rincón, E., Huante, P. and Ramírez, Y. (1993) Influence of Vesicular-Arbuscular Mycorrhizae on Biomass Production by the Cactus Pachycereus pecten-aboriginum. Mycorrhiza, 3, 79-81. http://dx.doi.org/10.1007/BF00210697

[8] Pope, P.E. (1993) Some Soil Fungi Are Beneficial to Tree Seedling Growth. Forestry and Natural Resources, Woodland Management, Purdue University. http://www.extension.purdue.edu/extmedia/FNR/FNR-104.html

[9] Dubrovsky, J.G. and North, G.B. (2002) Root Structure and Function. In: Nobel, P.S., Ed., Cacti-Biology and Uses, University of California Press, Berkeley and Los Angeles, 41-56.

[10] Barrow, J.R., Lucero, M.E., Reyes-Vera, I. and Havstad, K.M. (2008) Do Symbiotic Microbes Have a Role in Plant Evolution, Performance and Response to Stress? Communicative \& Integrative Biology, 1, 69-73. http://dx.doi.org/10.4161/cib.1.1.6238

[11] Orozco-Segovia, A., Márquez-Guzmán, J., Sánchez-Coronado, M.E., De Buen, A.G., Baskin, J.M. and Baskin, C.C. (2007) Seed Anatomy and Water Uptake in Relation to Seed Dormancy in Opuntia tomentosa (Cactaceae, Opuntioideae). Annals of Botany, 99, 581-592.

[12] Delgado-Sánchez, P., Ortega-Amaro, M.A., Rodríguez-Hernández, A.A., Jiménez-Bremont, J.F. and Flores, J. (2010) Further Evidence from the Effect of Fungi on Breaking Opuntia Seed Dormancy. Plant Signaling and Behavior, 5, 1229-1230. http://dx.doi.org/10.4161/psb.5.10.12835

[13] Delgado-Sánchez, P., Ortega-Amaro, M.A., Jiménez-Bremont, J.F. and Flores, J. (2011) Are Fungi Important for Breaking Seed Dormancy in Desert Species? Experimental Evidence in Opuntia streptacantha (Cactaceae). Plant Biology, 13, 154-159. http://dx.doi.org/10.1111/j.1438-8677.2010.00333.X

[14] Mandujano, M.C., Montaña, C. and Rojas-Aréchiga, M. (2005) Breaking Seed Dormancy in Opuntia rastrera from the Chihuahuan Desert. Journal of Arid Environments, 62, 15-21. http://dx.doi.org/10.1016/j.jaridenv.2004.10.009

[15] Salehi, M.R., Ashiri, F. and Salehi, H. (2008) Effect of Different Ethanol Concentrations on Seed Germination of Three Turfgrass Genera. Advances in Natural and Applied Sciences, 2, 6-9.

[16] Vierheilig, H., Coughlan, A.P., Wyss, U. and Piche, Y. (1998) Ink and Vinegar, a Simple Staining Technique for Arbuscular-Mycorrhizal Fungi. Applied and Environmental Microbiology, 64, 5004-5007.

[17] Shekhawat, K.K., Rao, D.V. and Batra, A. (2013) In Vitro Antimicrobial Activities of Endophytic Fungi Isolates from Medicinal Tree-Melia azedarach L. Journal of Microbiology Research, 3, 19-24.

[18] Kumar, A. (2012) The Influence of Bioinoculants on Growth and Mycorrhizal Occurrence in the Rhizosphere of Mentha spicata Linn. Bulletin of Environment, Pharmacology and Life Sciences, 1, 60-65.

[19] Hijri, M., Redecker, D., McDonald-Comber Petetot, J.A., Voigt, K., Wöstemeyer, J. and Sanders, I.R. (2002) Identification and Isolation of two Ascomycete Fungi from Spores of the Arbuscular Mycorrhizal Fungus Scutellospora castanea. Applied and Environmental Microbiology, 68, 4567-4573. http://dx.doi.org/10.1128/AEM.68.9.4567-4573.2002

[20] De Jaeger, N., Declerck, S. and de la Providencia, I.E. (2010) Mycoparasitism of Arbuscular Mycorrhizal Fungi: A Pathway for the Entry of Saprotrophic Fungi into Roots. FEMS Microbiology Ecology, 73, 312-322.

[21] Schenck, N.C. and Smith, G.S. (1982) Additional New and Unreported Species of Mycorrhizal Fungi (Endogonaceae) from Florida. Mycologia, 77, 77-92.

[22] Martínez-Medina, A., Pascual, J.A., Pérez-Alfocea, F., Albacete, A. and Roldán, A. (2010) Trichoderma harzianum and Glomus intraradices Modify the Hormone Disruption Induced by Fusarium oxysporum Infection in Melon Plants. Phytopathology, 100, 682-688. http://dx.doi.org/10.1094/PHYTO-100-7-0682

[23] Ellouze, W., Hamel, C., Freire Cruz, A., Ishii, T., Gan, Y., Bouzid, S. and St-Arnaud, M. (2012) Phytochemicals and Spore Germination: At the Root of AMF Host Preference? Applied Soil Ecology, 60, 98-104. http://dx.doi.org/10.1016/j.apsoil.2012.02.004

[24] Dastager, S.G., Deepa, C.K. and Pandey, A. (2010) Isolation and Characterization of Novel Plant Growth Promoting Micrococcus sp. NII-0909 and Its Interaction with Cowpea. Plant Physiology and Biochemistry, 48, 987-992. http://dx.doi.org/10.1016/j.plaphy.2010.09.006

[25] Clarkson, J.P., Scruby, A., Mead, A., Wright, C., Smith, B. and Whipps, J.M. (2006) Integrated Control of Allium White Rot with Trichoderma viride, Tebuconazole and Composted Onion Waste. Plant Pathology, 55, 375-386. http://onlinelibrary.wiley.com/doi/10.1111/j.1365-3059.2006.01389.x/full 
http://dx.doi.org/10.1111/j.1365-3059.2006.01389.x

[26] Küçük, C., Kivanç, M. and Kinaci, G. (2007) Biological Efficacy of Trichoderma harzianum Isolate to Control Some Fungal Pathogens of Wheat (Triticum aestivum) in Turkey. Biologia, 62, 283-286. http://dx.doi.org/10.2478/s11756-007-0049-9

[27] Bouziane, Z., Dehimat, L., Abdelaziz, W., Benabdelkader, M. and Kacem Chaouche, N. (2011) The Antagonism between Trichoderma viride and Other Pathogenic Fungal Strains in Zea mays. Agriculture and Biology Journal of North America, 2, 584-590. http://dx.doi.org/10.5251/abjna.2011.2.4.584.590

[28] Sjöberg, J. (2005) Arbuscular Mycorrhizal Fungi-Occurrence in Sweden and Interaction with a Plant Pathogenic Fungus in Barley. Ph.D. Thesis, Swedish University of Agricultural Sciences, Uppsala, Acta Universitatis Agriculturae Sueciae, 33.

[29] Dalling, J.W., Davis, A.S., Schutte, B.J. and Arnold, E.A. (2011) Seed Survival in Soil: Interacting Effects of Predation, Dormancy and the Soil Microbial Community. Journal of Ecology, 99, 89-95.

http://dx.doi.org/10.1111/j.1365-2745.2010.01739.x 
Scientific Research Publishing (SCIRP) is one of the largest Open Access journal publishers. It is currently publishing more than 200 open access, online, peer-reviewed journals covering a wide range of academic disciplines. SCIRP serves the worldwide academic communities and contributes to the progress and application of science with its publication.

Other selected journals from SCIRP are listed as below. Submit your manuscript to us via either submit@scirp.org or Online Submission Portal.
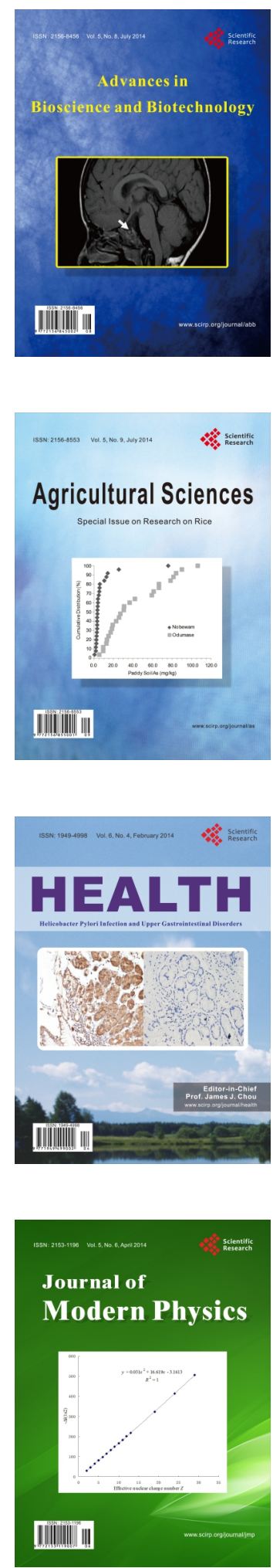
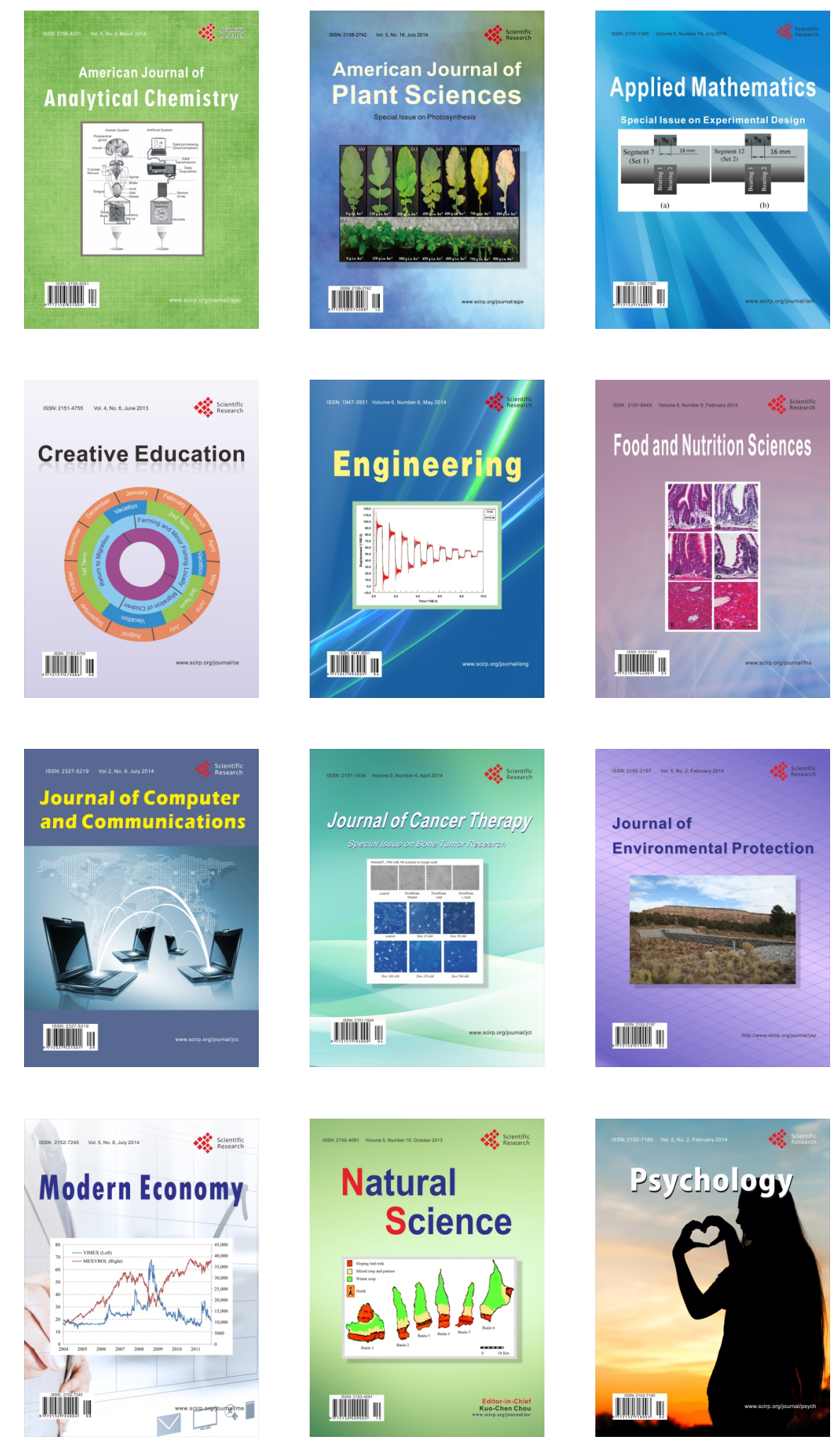